\title{
CORRESPONDENCE
}

We welcome letters to the Editor concerning articles which have recently been published. Such letters will be subject to the usual stages of selection and editing; where appropriate the authors of the original article will be offered the opportunity to reply.

Letters should normally be under 300 words in length, double-spaced throughout, signed by all authors and fully referenced. The edited version will be returned for approval before publication.

\section{THE PROGNOSIS FOR WALKING IN OSTEOGENESIS IMPERFECTA}

Sir

We read with interest the paper by Daly et $\mathrm{al}^{1}$ in the May 1996 issue entitled 'The prognosis for walking in osteogenesis imperfecta'. They found that sitting by the age of ten months was a strong predictor of future walking ability, and that those who start walking late tend not to use it as their primary means of mobility. We were particularly interested in their finding that intramedullary rodding had no major influence on motor development. These suggestions stimulated us to review our experience of such patients at the Sheffield Children's Hospital using the same prognostic markers.

Our review of 24 children confirmed that sitting by the age of ten months was a good predictor of walking ability; $75 \%$ of these children had managed some walking before rodding. Of those with delayed independent sitting, none had walked.

We disagree, however, with their suggestion that intramedullary rodding does not affect the motor development. In our group nine patients are now walking who had never done so before rodding and there are a further six who had previously been wheelchairbound because of recurrent fractures on attempting to walk. We have also found that in patients in whom walking was established late, it has remained the primary means of mobility at a median follow-up of 55 months from operation. Other workers have found significant improvements in walking ability after this procedure. $^{2-6}$

Intramedullary rodding for osteogenesis imperfecta improves motor development in a significant group of patients and has a profound effect on their social development and integration into society.

J. M. WILKINSON, FRCS

B. W. SCOTT, FRCS Orth

M. J. BELL, MD, FRCS

Sheffield Children's Hospital

Sheffield, UK

1. Daly K, Wisbeach A, Sanpera I Jr, Fixsen JA. The prognosis for walking in osteogenesis imperfecta. J Bone Joint Surg [Br] 1996; 78-B:477-80.

(C)1997 British Editorial Society of Bone and Joint Surgery 0301-620X/97/27594\$2.00

J Bone Joint Surg [Br] 1997;79-B:339-43.
2. Binder H, Conway A, Hason S, et al. Comprehensive rehabilitation of the child with osteogenesis imperfecta. Am J Med Genet 1993; 45:265-9.

3. Lang-Stevenson AI, Sharrard WJW. Intramedullary rodding with Bailey-Dubow extensible rods in osteogenesis imperfecta: an interim report of results and complications. J Bone Joint Surg [Br] 1984; 66-B:227-32.

4. Nicholas RW, James P. Telescoping intramedullary stabilisation of the lower extremities for severe osteogenesis imperfecta. J Paediatr Orthop 1990;10:219-23.

5. Marafioti RL, Westin GW. Elongating intramedullary rods in the treatment of osteogenesis imperfecta. J Bone Joint Surg [Am] 1977; 59-A:467-72.

6. Rodriguez RP, Bailey RW. Internal fixation of the femur in patients with osteogenesis imperfecta. Clin Orthop 1981;159:126-33.

Authors' reply:

Sir

We thank Messrs Wilkinson, Scott and Bell for their response to our paper, and confirmation that sitting by the age of ten months was a good prognostic indicator of walking.

We studied a particularly severely affected group and feel that it is important to identify those children who stand and make attempts to walk but fail because of recurrent fractures. We agree that intramedullary rodding is definitely of benefit in this group. In our patients, however, there were a significant number of children who had not managed independent sitting by the age of ten months and subsequently underwent rodding, but still never walked independently. It is important in this group to differentiate between failure to walk because of recurrent fractures and deformity of the long bones and inability to do so because of other manifestations of osteogenesis imperfecta.

Repeated fractures of the bone or disabling deformity are good indications for intramedullary rodding, but the procedure is inappropriate in a child whose early motor development is significantly delayed, and in whom independent sitting has not been established at ten months in the absence of recurrent fractures or significant deformity. We feel that such surgery with its inherent difficulties and complications is not justified on the grounds of delayed development alone, and we found no evidence that intramedullary rodding could improve the prognosis for walking in this group of patients.

K. DALY, FRCS(Orth)

J. A. FIXSEN, MChir, FRCS

The Hospital for Sick Children

Great Ormond Street

London, UK.

\section{COMPARISON OF TWO CONSERVATIVE METHODS OF TREATING AN ISOLATED FRACTURE OF THE LATERAL MALLEOLUS}

Sir, We read with interest the paper by Port et al ${ }^{1}$ in the July 1996 issue entitled 'Comparison of two conservative methods of treating an isolated fracture of the lateral malleolus'. We wish to take issue with two points arising from the article. 
First, although Lauge-Hansen described a supination-eversion injury in his original classification of ankle fractures, ${ }^{2}$ the actual mechanism of injury was external rotation of the talus, the result of which is illustrated in Figure 1 of the paper by Port et $\mathrm{al}^{1}$. Modern nomenclature refers to this as a supination-external rotation injury, ${ }^{3,4}$ and we would urge the universal adoption of the term to avoid confusion regarding the pathogenesis of this fracture.

The authors state that in the pattern of injury studied, the lateral malleolus is the first structure to fail. This contradicts LaugeHansen's study which clearly showed that rupture or avulsion of the anterior tibiofibular ligament preceded lateral malleolar injury.

\section{R. L. WILLIAMS, FRCS Orth}

F. S. HADDAD, BSc, FRCS

Royal National Orthopaedic Hospital Trust

Stanmore, UK.

1. Port AM, McVie JL, Naylor G, Kreibich DN. Comparison of two conservative methods of treating an isolated fracture of the lateral malleolus. J Bone Joint Surg [Br] 1996;78-B:568-72.

2. Lauge-Hansen $\mathbf{N}$. Fractures of the ankle II: combined experimental/ surgical and experimental roentgenologic investigation. Arch Surg 1950;60:957-85.

3. Pettrone FA, Gail M, Fee D, Fitzpatrick T, Van Herpe LD. Quantitative criteria for prediction of the results after displaced fractures of the ankle. J Bone Joint Surg [Am] 1983;65-A:667-77.

4. Browner BD, Jupiter JB, Levine AN, Trafton PG. Skeletal trauma. Vol. 2, First ed. Philadelphia, etc: WB Saunders, 1992:1892.

\section{Author's reply:}

Sir,

We thank Mr Williams and Mr Haddad for their interest in the article and fully agree that the mechanism is one of external rotation of the talus. We prefer, however, to use the AO nomenclature as we find this is simpler, more reproducible and also dictates options for treatment. The anterior tibiofibular ligament is not always ruptured and can even be partially ruptured. ${ }^{1}$ When the ligament is inspected at operation during the fixation of type-B2 injuries it is often partially torn through its relatively broad insertion on the anterior aspect of the fibula.

A. M. PORT, FRCS

Middlesbrough General Hospital

Middlesbrough, UK.

1. Geissler WB, Tsao AK, Hughes JL. Rockwood and Green fractures in adults. Vol 2. 4th edition. Philadelphia, etc: Lippincott-Raven, 1996:2201-66.

\section{THE EFFECTS OF PARTICULATE POLYETHYLENE AT A WEIGHT-BEARING BONE-IMPLANT INTERFACE}

Sir,

We read with interest the article entitled 'The effects of particulate polyethylene at a weight-bearing bone-implant interface' by Allen et $\mathrm{al}^{1}{ }^{1}$, which was published in the January 1996 issue.

The model proposed by Allen et al is certainly useful, although it eliminates movement of the implant and places the implant in a weight-bearing area. The study, however, has a considerable drawback in that the authors have not ruled out infection by aerobic and anaerobic cultures which are the most important tests in the diagnosis of periprosthetic infection. ${ }^{2}$ Infection itself may result in bone resorption and membrane formation and it cannot be ruled out only by histopathological studies.

M. KARAHAN, MD

T. ESEMENLI, MD

School of Medicine, Marmara University

Istanbul, Turkey.

1. Allen M, Brett F, Millett P, Rushton N. The effects of particulate polyethylene at a weight-bearing bone-implant interface. $J$ Bone joint Surg [Br] 1996;78-B:32-7.

2. Paprovsky WG, Bradford MS, Jablonsky WS. Cementless revision total hip arthroplasty. In: Callaghan JJ, Dennis DA, Paprosky WG, Rosenberg AG, eds. Orthopedic knowledge update: hip and knee reconstruction. Rosemont: AAOS, 1995;II:215-25.

\section{Author's reply:}

Sir,

We thank Drs Karahan and Esemenli for their comments.

We agree that in the clinical setting the diagnosis of sepsis is rarely, if ever, made solely on the grounds of a histopathological examination. It is well recognised, however, that the results of bacteriological cultures can be potentially misleading. Padgett et $\mathrm{al}^{1}$ recently compared the sensitivity and accuracy of intraoperative cultures from tissue samples with histological examination as a means of diagnosing infection around total joint replacements. In a study of 138 consecutive revision arthroplasties of the hip there were 42 positive cultures, but only one joint ultimately developed sepsis. The infected hip was the only one to show histological evidence of acute inflammation, while the remainder all showed signs of chronic inflammation consistent with aseptic loosening. The overall positive predictive value of cultures was $2.4 \%$ in this series of hips, a result which prompted the authors to conclude that "positive intraoperative cultures are an unreliable predictor of sepsis and that permanent histologic sectioning is a more useful tool in determining sepsis". Although the use of aerobic and anaerobic cultures may have made the study more relevant clinically, it is unlikely that they would have been of significant benefit in the accurate diagnosis of infection in these animals. None of the rats received antibiotic therapy for more than 24 hours after operation and no antibiotics were used after the intra-articular injections. We are confident that if sepsis was responsible for the bone resorption in our model, we would have seen evidence of acute inflammation. Mirra et $\mathrm{al}^{2}$ found the histological changes of acute inflammation in all of 15 patients with positive joint cultures and recommended that "all tissues in which polys are noted by the pathologist must be cultured". None of the specimens from our pilot study showed evidence of polymorphonuclear leucocyte infiltration, so none was cultured.

The small size of the knee in the rat makes harvesting of sterile samples of tissue difficult. If one of the specimens had produced a positive culture it is likely that this would have been the result of contamination. Rather than eliminating animals from the study on the basis of a possible false-positive result, we prefer to culture samples when the histological appearances have provoked suspicion. It may be more thorough to perform both cultures and tissue examination concurrently, but we feel that our regimen of histological assessment followed by bacteriological cultures if indicated is appropriate for the diagnosis of sepsis in our animal model.

M. J. ALLEN, MA, VetMB, PhD, MRCVS

Addenbrooke's Hospital

Cambridge, UK.

1. Padgett DE, Silverman A, Schjowicz F, Simpson RB, Rosenberg AG, Galante JO. Efficacy of intraoperative cultures obtained during revision total hip arthroplasty. J Arthroplasty 1995;10:420-6. 
2. Mirra J, Amstutz HC, Matos M, Gold R. The pathology of joint tissues and its clinical relevance in prosthesis failure. Clin Orthop 1976;117:221-40.

\section{THERMAL NECROSIS AFTER TIBIAL REAMING}

Sir,

The article in the July 1996 issue by Leunig and Hertel ${ }^{1}$ entitled 'Thermal necrosis after tibial reaming for intramedullary nail fixation' describes three cases of osteonecrosis after presumed thermal damage during reaming. I have some comments to make about the conclusions presented.

First, at no stage is there any direct evidence that thermal injury was responsible for the subsequent problems in soft tissues and bone; the reamer was not described as excessively hot after its removal from the medullary cavity nor did the bone smoke. No objective measurements were made of the temperature of the reamers compared with those used in patients with an uncomplicated recovery and the time over which the problems developed is not stated. Thus, the evidence is circumstantial that the subsequent damage was due to thermal energy rather than infection introduced at the time of surgery.

Secondly, the authors conclude that "if reamed intramedullary nailing is to be undertaken ... the diameter of the intramedullary cavity must be assessed on preoperative radiographs". This important point is not supported by any objective advice as to what constitutes a critical size at which to avoid reaming.

Finally, in the first two cases the fractures are in perfect alignment and thus these closed injuries could have been treated conservatively with, for example, a Sarmiento cast. The choice of internal fixation in these circumstances seems unwise.

Thermal damage after intramedullary nailing of the tibia has not been noted before to my knowledge. The authors are to be congratulated on bringing this topic to the attention of a wider audience.

\section{R. M. DODENHOFF, FRCS}

Taunton \& Somerset Hospital Taunton, UK.

1. Leunig M, Hertel R. Thermal necrosis after tibial reaming for intramedullary nail fixation: a report of three cases. J Bone Joint Surg [Br] 1996;78-B:584-7.

Authors' reply:

Sir,

We thank Mr Dodenhoff for his comments regarding our paper. We will address the points in order.

The study was performed retrospectively, analysing charts of patients presenting with a pretibial cutaneous blister following operation at the first dressing after 48 hours. During reaming of the medullary cavity temperature measurements are not usually taken. Each surgeon experienced difficulty in advancing the reamer. Although there is no direct evidence for thermal necrosis, the time of appearance, the location of the blister and the later necrosis strongly suggest thermal damage rather than local infection as the cause of the tissue damage. Two patients had a segmental necrosis several centimetres distal to the fracture site where the medullary canal was narrowest.

We did wish to proscribe a particular diameter of the medullary canal as a threshold for intramedullary reaming since this was one of several causative factors. If, however, the diameter of the canal is less than the smallest available reamer and nail, an alternative procedure should be considered. Bluntness and excessive pressure on the reamer will further increase the degree of friction-induced heat at the tip of the reamer.

It was not within the scope of the paper to discuss indications for treatment and procedures of a certain type of fracture. Only case 1 had primary treatment in our hospital.

M. LEUNIG, MD

R. HERTEL, MD

University of Berne,

Berne, Switzerland.

Sir

I read with interest the article in the July 1996 issue by Leunig and Hertel ${ }^{1}$ entitled 'Thermal necrosis after tibial reaming'. I agree with the authors' conclusions. I have published the results of operating without a tourniquet in plating tibial fractures ${ }^{2}$ and inserting knee replacements. ${ }^{3}$ It is clear that a bloodless field can be detrimental to the healing of both bone and soft tissues. Drying of ischaemic tissues by exposure and thermal damage from power instruments contribute to this. A tourniquet is not required for tibial nailing and is probably overused in routine orthopaedic practice, especially when there is any doubt about tissue or bone perfusion.

K. S. EYRES, MD, FRCS Orth

Princess Elizabeth Hospital

Exeter, UK.

1. Leunig M, Hertel R. Thermal necrosis after tibial reaming for intramedullary nail fixation: a report of three cases. J Bone Joint Surg [Br] 1996;78-B:584-7.

2. Salam AA, Eyres KS, Cleary J. The use of a tourniquet when plating tibial fractures. J Bone Joint Surg [Br] 1991;73-B:86-7.

3. Abdel-Salam A, Eyres KS. The effects of tourniquet during total knee arthroplasty: a prospective randomised study. J Bone Joint Surg $[\mathrm{Br}]$ 1995;77-B:250-3.

Authors' reply:

Sir,

Thank you for your interest in our article and your comment regarding the intraoperative use of a tourniquet. This, among other factors, compromises tissue integrity by a global shut-down of blood flow abolishing heat transfer and leading to drying of exposed tissue. A tourniquet should be used only if a bloodless field is required for optimising surgery and is only one of several factors, including a narrow cavity and aggressive reaming, which lead to severe osteocutaneous necrosis of the tibia.

M. LEUNIG, MD

R. HERTEL, MD

University of Berne

Berne, Switzerland.

\section{CHRONIC ANTERIOR GLENOHUMERAL INSTABILITY}

Sir,

Walch, in his Instructional Course Lecture, ${ }^{1}$ advocates CT and CT-arthrography for further evaluation of glenohumeral instability, and performs arthroscopy only when clinical and imaging examinations fail to confirm the diagnosis. CT and CT-arthrography have the disadvantages of increased ionising radiation, of being invasive and having only limited diagnostic use. Arthroscopy needs a long learning curve in addition to being invasive and expensive. 
MRI is a non-invasive diagnostic tool with no ionising radiation, excellent contrast resolution and the ability to produce multiplanar images. The inherent capability of MRI in the delineation of soft-tissue anatomy together with osseous structures makes it suitable for evaluating glenohumeral abnormalities such as lesions of the labrum ${ }^{2,3}$ and the Hill-Sachs lesion. ${ }^{4}$

We consider that the conventional diagnostic methods have no significant advantages over MRI except their lower expense.

\section{A. ÖZNUR, MD \\ G. KARAKURUM, MD \\ A. M. TOKGÖZOGLU, MD \\ Hacettepe University Hospital \\ Ankara, Turkey.}

1. Walch G. Chronic anterior glenohumeral instability. J Bone Joint Surg [Br] 1996;78-B:670-7.

2. Leeger LL, Gold RH, Bassett LW. Shoulder instability: evaluation with MR imaging. Radiology 1988;168:695-7.

3. Iannotti J, Zlatkin MB, Esterhan JL, et al. MRI of the shoulder: sensitivity, specificity and predictive value. J Bone Joint Surg [Am] 1991;73-A::17-29.

4. Workman TL, Burkhard TK, Resnick D, et al. Hill-Sachs lesion: comparison of detection with MR imaging, radiography and arthroscopy. Radiology 1992;185:847-52.

\section{Author's reply:}

Sir

I thank our colleagues from Turkey for their comments concerning my Instructional Course Lecture entitled 'Chronic anterior glenohumeral instability'.

I agree that with the use of a high field strength magnet, properly designed surface coils and with good homogeneity of the magnetic field, MRI is a promising tool in the diagnosis of glenohumeral instability if a specialised radiologist is available. In the absence of such a person, however, CT arthrography is more likely to give the appropriate information. This procedure is particularly useful in demonstrating the typical Bankart or bony Bankart lesions. I therefore advocated the use of CT-arthrography rather than MRI.

G. WALCH, MD

Clinique Émilie de Vialar

Lyon, France.

\section{HIP ABNORMALITIES DETECTED BY ULTRASOUND}

Sir

I read with interest the paper in the July 1996 issue entitled 'Hip abnormalities detected by ultrasound in clinically normal newborn infants' by Terjesen et $\mathrm{al}^{1}$ which followed the progress of a group of clinically normal infants in whom ultrasound examination revealed abnormalities. The authors concluded that newborn infants with a normal clinical examination do not need treatment from birth despite abnormalities detected on ultrasound examination. I am concerned that the wrong message may be drawn from the conclusions presented.

Clinical screening for developmental dysplasia of the hip (DDH) leads to overtreatment, and a number of studies have shown that it is possible to reduce this by careful ultrasound examination to define whether an abnormality is present. ${ }^{2}$ This can only be successful, however, if children with observed abnormalities are subject to rigorous and regular orthopaedic review and it is noteworthy that in the series of Terjesen et al, 15 patients ultimately required treatment. It is debatable whether the results would have been as good under the UK system of subsequent examination in the community by possibly inexperienced general practitioners, as in most centres an initial normal clinical examination would mean no further contact with a paediatric orthopaedic surgeon.

Terjesen et al are to be congratulated in their efforts to reduce the overtreatment of DDH but it must not be thought that a normal clinical examination at birth implies a benign outcome. Continuing vigilance by the orthopaedic community and the use of the appropriate investigation of neonatal hip ultrasound are mandatory.

\section{R. M. DODENHOFF, FRCS}

Taunton \& Somerset Hospital

Taunton, UK.

1. Terjesen T, Holen KJ, Tegnander A. Hip abnormalities detected by ultrasound in clinically normal newborn infants. J Bone Joint Surg [Br] 1996;78-B:636-40.

2. Boeree NR, Clarke NMP. Ultrasound imaging and secondary screening for congenital dislocation of the hip. $J$ Bone Joint Surg $[\mathrm{Br}]$ 1994:76-B:525-33.

\section{Author's reply:}

Sir,

I thank Mr Dodenhoff for his comments regarding our paper on the natural history of hip abnormalities detected by ultrasound in clinically normal newborn infants. We concluded that such infants do not need treatment from birth because in most spontaneous normalisation occurred.

I agree with Mr Dodenhoff that ultrasound is of value in distinguishing between clinically unstable hips that need treatment from those that do not, and that a normal clinical examination at birth does not always imply a benign outcome, especially if inexperienced examiners carry out the tests. In our study the infants were managed by experienced paediatricians and paediatric orthopaedic surgeons. Under such conditions our conclusions are valid and if the hips are found to be normal, routine follow-up by orthopaedic surgeons is not necessary. All infants with abnormal or suspicious hips that are not treated, however, are followed up by the orthopaedic surgeons, using clinical and ultrasound examinations and, if necessary, also radiography, and not by inexperienced practitioners.

If optimal quality in the primary screening and follow-up is available, abnormal hips can be detected by ultrasound in clinically normal infants and overtreatment avoided by awaiting spontaneous development in hips with abnormal or suspicious ultrasound findings and normal clinical findings, and vice versa.

T. TERJESEN, MD, PhD

The National Hospital

Oslo, Norway.

\section{ACETABULAR CUP MIGRATION: PREDICTION OF ASEPTIC LOOSENING}

Sir

In your November 1995 issue you published our paper on 'Acetabular cup migration: prediction of aseptic loosening'. In this we reported a direct relationship between the vertical migration of acetabular components at two years and the incidence of aseptic loosening at a minimum of five years.

Since then we have published the two-year migration rates for press-fit and partially HA-coated acetabular components. We found them to be more stable than the previously reported 


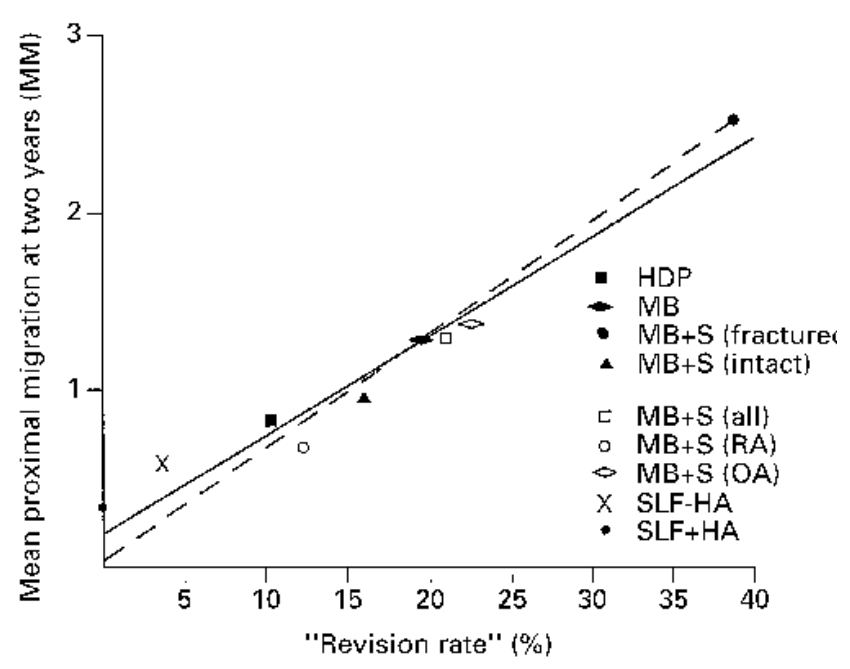

Fig. 1

The relationship between mean proximal migration at two years and the 'revision rate' for various acetabular prostheses. Details of the revision rate and the first seven prostheses listed in the key are given in Stocks et al. ${ }^{1}$ The two prostheses now added are shown as 'SLF-HA and SLF+HA'. The best-fit straight line from Stocks et al is dotted, and the new best-fit straight line is solid.

sockets. $^{2}$

I now write to report that enough of these new components have been reviewed at five years to show a revision rate of zero at that time. This finding enables us to extend our previous graph and to confirm the direct relationship between early migration and the revision rate for a range of sockets of widely differing stability (Fig. 1). We hope that others will be able to add similar data for other prostheses.

M. A. R. FREEMAN, MD, FRCS

Royal London Hospital Medical College

London, UK.
1. Stocks GW, Freeman MAR, Evans SJW. Acetabular cup migration: prediction of aseptic loosening. J Bone Joint Surg [Br] 1995;77-B: 853-61,

2. Moilanen T, Stocks GW, Freeman MAR, et al. Hydroxyapatite coating of an acetabular prosthesis: effect on stability. J Bone Joint Surg [Br] 1996;78-B:200-5.

\section{CONGENITAL DISLOCATION OF THE HIP IN EXTRAUTERINE PREGNANCY}

Sir,

I was very interested to read the article published in the September 1996 issue entitled 'Congenital dislocation of the hip in extrauterine pregnancy' by Uglow and Clarke. ' I have reported a very similar case in a previous paper in $1985^{2}$ and came to identical conclusions.

\section{R. KOHLER \\ Hôpital Édouard Herriot \\ Lyon, France.}

1. Uglow MG, Clarke NMP. Congenital dislocation of the hip in extrauterine pregnancy. J Bone Joint Surg [Br] 1996;78-B:751-3.

2. Kohler R. Luxation congénitale de la hanche chez un nouveau-né après grossesse tubaire (foeto-salpynx). Rev Chir Orthop 1985; 71:393-6.

\section{Author's reply:}

Sir,

I thank Professor Kohler for his letter. I can only apologise that this paper did not surface in our extensive review of the literature which we thought was complete. As he suggests, his conclusions were similar and I have pleasure in acknowledging his contribution.

N. M. P. CLARKE, ChM, FRCS

Southampton General Hospital

Southampton, UK. 